Article

\title{
Structural Characterization and Antioxidant Potential of Chitosan by $\gamma$-Irradiation from the Carapace of Horseshoe Crab
}

\author{
Siddhartha Pati ${ }^{1,2, * \mathbb{C}}$, Anil Chatterji ${ }^{3,4}$, Bisnu Prasad Dash ${ }^{1,5}$, Bryan Raveen Nelson ${ }^{2,3, *}$, \\ Tanmay Sarkar ${ }^{6,7} \mathbb{D}^{\mathbb{D}}$, Salwa Shahimi ${ }^{8}$, Hisham Atan Edinur ${ }^{9, *} \mathbb{0}$, \\ Teh Sabariah Binti Abd Manan ${ }^{2}$, Paramananda Jena ${ }^{5}$, Yugal Kishore Mohanta ${ }^{3}$ and \\ Diptikanta Acharya ${ }^{10}$
}

1 Horseshoe Crab Research Unit, Department of Bioscience \& Biotechnology, Fakir Mohan University, Balasore 756089, Odisha, India; bisnubsbtfmu@gmail.com

2 Institute of Tropical Biodiversity and Sustainable Development, University Malaysia Terengganu, Kuala Nerus 21030, Terengganu, Malaysia; tehsabariah@umt.edu.my

3 Research Divisions, Association for Biodiversity Conservation and Research, Devine Colony, Balasore 756001, Odisha, India; abioconservation@gmail.com or anilchatterji@gmail.com (A.C.); ykmohanta@gmail.com (Y.K.M.)

4 Aquamarina Research Foundation, Dona Paula, Panaji 403004, Goa, India

5 Centre of Excellence (CoE) for Bioresource Management and Energy Conservation Material Development, Fakir Mohan University, Balasore 756089, Odisha, India; parama.pondy@gmail.com

6 Department of Food Technology and Biochemical Engineering, Faculty of Engineering and Technology, Jadavpur University, Jadavpur, Kolkata 700032, West Bengal, India; tanmays468@gmail.com

7 Malda Polytechnic, West Bengal State Council of Technical Education, Govt. of West Bengal, Malda 732102, West Bengal, India

8 School of Marine and Environmental Sciences, University Malaysia Terengganu, Kuala Nerus 21030, Terengganu, Malaysia; salwa.shahimi@umt.edu.my

9 Forensic Science Programme, School of Health Sciences, Universiti Sains Malaysia, Health Campus, Kubang Kerian 16150, Kelantan, Malaysia

10 School of Biotechnology, GIET University, Gunupur 765022, Odisha, India; dacharya249@gmail.com

* Correspondence: patisiddhartha@gmail.com (S.P.); bryan.nelson@umt.edu.my (B.R.N.); edinur@usm.my (H.A.E.)

Received: 4 August 2020; Accepted: 15 September 2020; Published: 15 October 2020

\begin{abstract}
Natural product extraction is ingenuity that permits the mass manufacturing of specific products in a cost-effective manner. With the aim of obtaining an alternative chitosan supply, the carapace of dead horseshoe crabs seemed feasible. This sparked an investigation of the structural changes and antioxidant capacity of horseshoe crab chitosan $(\mathrm{HCH})$ by $\gamma$-irradiation using ${ }^{60}$ Co source. Chitosan was extracted from the horseshoe crab (Tachypleus gigas; Müller) carapace using heterogeneous chemical $\mathrm{N}$-deacetylation of chitin, followed by the irradiation of $\mathrm{HCH}$ using ${ }^{60} \mathrm{Co}$ at a dose-dependent rate of $10 \mathrm{kGy} / \mathrm{hour}$. The average molecular weight was determined by the viscosimetric method. Regarding the chemical properties, the crystal-like structures obtained from $\gamma$-irradiated chitosan powders were determined using Fourier transfer infrared (FTIR) spectroscopy and X-ray diffraction (XRD) analyses. The change in chitosan structure was evident with dose-dependent rates between 10 and $20 \mathrm{kGy} / \mathrm{hour}$. The antioxidant properties of horseshoe crab-derived chitosan were evaluated in vitro. The $20 \mathrm{kGy} \gamma$-irradiation applied to chitosan changed the structure and reduced the molecular weight, providing sufficient degradation for an increase in antioxidant activity. Our findings indicate that horseshoe crab chitosan can be employed for both scald-wound healing and long-term food preservation due to its buffer-like and radical ion scavenging ability.
\end{abstract}


Keywords: biopolymer; antioxidant; preservative; chitin; scavenging; natural product

\section{Introduction}

Chitin is the second most abundant biopolymer after cellulose, made of polysaccharides, and can be found in the cell wall of eukaryotes (i.e., fungi, yeast, protists, and diatoms). It is also an important substance for exoskeleton buildup in most invertebrates, including sponges, worms, molluscs, and arthropods. The commercial production of chitin is possible through crustacean (shrimp, crab, prawn, and crayfish) outer skeleton extractions [1-4]. In recent years, chitin applications have been scenic due to its remarkable biodegradability and biocompatibility properties, for example in cosmetics; pharmacy and medicine; biomaterial engineering; agriculture, textile, and paper industries; and environmental engineering [5-9]. Overall, chitin and its derivatives-mainly chitosan-are associated with more than 200 potential applications [10]. Generally, the industrial application of chitin involves alkaline hydrolysis, which is a procedure in which chitin is converted into a soluble polymer called chitosan. The polymer stimulates antimicrobial activity and is considered to be a significant crystalline homopolymer of $\mathrm{N}$-acetyl glucosamine renewable sources [11].

The Indian horseshoe crab possesses a tough exoskeleton that offers protection from predators. To attain this feature, millions of tightly interwoven cellulose-like strands called chitin are orientated as tough and flexible glue and adhere to each other to form a shell. The chitin of horseshoe crab is favored for research and sought over other arthropod chitin because of its comparatively better purity [12]. Presently, the utilization of chemicals for food preparation is displaying an increasing demand. Therefore, food industries are turning their attention towards natural materials that preserve food from contamination from microbes. With the focus on this aspect, chitosan preparations are outlined considering their efficacy and safety, particularly when utilized as preservatives in the food industry. In this regard, chitosan seems effective for inhibiting microbial growth, promoting its use as a food preservative [13]. Since food and food-borne microbes are $\mathrm{pH}$-sensitive, the ability of chitosan to regulate sodium ions in food makes it a suitable buffer that arrests microbial activity [14]. While $\gamma$-irradiation has the ability to modify chemical and physical properties of some polymeric materials [15], its ability to break polymeric chains promotes its use for improving the solubility of solvents $[16,17]$ and stabilizing solutes $[18,19]$ for antimicrobial $[20]$ and antioxidant applications [21]. When $\gamma$-irradiation is applied to chitosan, the modification of chitosan molecules is thought to enhance the antimicrobial and antioxidant effects. However, knowledge on this form of application continues to be limited, apart from the application of chitosan comprised of different molecular weights for antioxidants [22] and antimicrobial [23,24] stimuli. We are also aware of the use of horseshoe crab chitosan as a bio-polymer, which has never been applied for the food industry [13]. Additionally, this form of chitosan has never been extracted, with the exception of our own findings [12]. In this study, the application of horseshoe crab chitosan against oxidative stress was conducted to identify the functional groups of $\gamma$-irradiated horseshoe crab chitosan. We evaluated the chitosan in terms of its molecular weight and determined its potential effect with regards to reducing the oxidative stress by defending the biotic or abiotic stress components.

\section{Materials and Methods}

\subsection{Irradiation of Chitosanwith $\gamma$-Radiation}

The carapace of dead horseshoe crabs was gathered, before crushing and grinding it into powder form. This was done to increase the surface area of exposure while converting chitin into chitosan by the following protocol $[12,25]$. After $24 \mathrm{~h}$ of storing the sample $\left(4^{\circ} \mathrm{C}\right.$ in a conventional refrigerator) in low-density polyethylene bags, the horseshoe crab chitosan $(\mathrm{HCH})$ was then separated into groups of different molecular weights using $\gamma$-irradiation treatment. In this step, ${ }^{60} \mathrm{Co}$ was administered 
in a dose-dependent manner of 10 and $20 \mathrm{kGy}$ and rate of $10 \mathrm{kGy} /$ hour using $\Gamma$-PX-30 irradiation cells. Verification of this step employed the Fricke dosimetry system, whereas the control system used Red Perspex dosimeters. The samples were stored in the dark at room temperature after $\gamma$-irradiation and were subjected to various characterization tests to evaluate the effects of radiation with sample properties.

\subsection{Determination of the Molecular Weight of Chitosan Using the Viscometric Method}

For investigating the effect of irradiation on chitosan in terms of viscosity, the average molecular weight $\left(\mathrm{M}_{\mathrm{V}}\right)$ was obtained by determining the intrinsic viscosity of chitosan solutions in $0.3 \mathrm{M}$ acetic acid/0.2 M sodium acetate at $25 \pm 0.5{ }^{\circ} \mathrm{C}$ using a reported method [26]. The measurement started with the determination of solvent flow times $\left(t_{0}\right)$ and continued with flow times of samples $\left(t_{n}\right)$. From these flow times, the relative viscosity $\left(\eta_{\mathrm{r}}\right)$, specific viscosity $\left(\eta_{\mathrm{sp}}\right)$, and reduced viscosity $\left(\eta_{\text {red }}\right)$ were calculated. The value of the intrinsic viscosity $(\eta)$ was calculated by extrapolating a plot of reduced viscosity against chitosan. Determinations were performed in triplicate using an Ubbelohde capillary viscometry technique and $\mathrm{M}_{\mathrm{v}}$ was calculated using the Mark-Houwink-Sakurada equation [6,27], which provides the relationship between the intrinsic viscosity and molecular weight:

$$
[\eta]=K\left(M_{V}\right)^{\alpha}
$$

where $[\eta]$ is the intrinsic viscosity, $\mathrm{M}_{\mathrm{v}}$ is the molecular weight, and $\mathrm{K}$ and $\alpha$ are constant. $\mathrm{K}=1.81 \times 10^{-3}$ and $\alpha=0.76$.

\subsection{Characterization of Chitosan Samples}

Chitosan's degree of deacetylation was determined using Fourier transform infrared spectroscopy (FTIR) (Thermo Nicolet ${ }^{\mathrm{TM}}$ 6700; Thermo Fisher Scientific, Waltham, MA, USA). In this step, the powder-form of chitosan was added with potassium bromide $(\mathrm{KBr}) w / w$ at $1: 1$, before being placed in a desiccator with silica beads to minimize moisture retention. It was incubated with 3 days oven drying (Memmert, Schwabach, Germany) before analysis using FTIR operating at a frequency of $4000-500 \mathrm{~cm}^{-1}$ and spectral range of $4 \mathrm{~cm}^{-1}$. The degree of deacetylation (DD) for chitosan was calculated as in Equation (1) [28].

$$
\mathrm{DD}=100-\left(\frac{\frac{\mathrm{A}_{1655}}{\mathrm{~A}_{3450}} \times 100}{1.33}\right)
$$

$\mathrm{A}_{1655}$ refers to the absorbance wavelength at $1655 \mathrm{~cm}^{-1}$ of the amide-I band. It was a measure of the $N$-acetyl group content. Meanwhile, $\mathrm{A}_{3450}$ refers to the absorbance wavelength at $3450 \mathrm{~cm}^{-1}$ of the hydroxyl band. The ratio was an internal standard used to correct the film thickness. The factor 1.33 refers to the ratio of $\mathrm{A}_{1655} / \mathrm{A}_{3450}$ for fully $\mathrm{N}$-acetylated chitosan [29].

Separately, another batch of horseshoe crab chitosan was stored in a desiccator with silica beads overnight, before being mounted in its powder form onto a goniometer. An X-ray Panalytical Diffractometer ( $X^{\prime}$ Pert Pro, Panalytical, Almelo, The Netherlands) operating with CuK $\alpha$ radiation $(40 \mathrm{kV}, 30 \mathrm{~mA})$ at a wavelength $\lambda$ of $1.54 \mathrm{~nm}$ continuously scanned the chitosan at a rate of $1^{\circ} /$ minute from $5-45^{\circ}$ over the $2 \theta$ range. Meanwhile, the chitosan stock was measured for its weight within the range of 5.2 and $5.4 \mathrm{mg}$, before being heated from 50 to $650{ }^{\circ} \mathrm{C}$ in the differential scanning colorimetric Pyris Diamond DSC (Perkin Elmer, Boston, MA, USA).

The thermogravimetry/differential thermal analysis (TG/DTA) was performed using a thermogravimetric analyzer (Pyris Diamond TG-DTA, PerkinElmer Instrument, Boston, MA, USA) with a heating rate of $10^{\circ} \mathrm{C} /$ minute and dynamic synthetic atmospheric air with a flow of $100 \mathrm{~mL} /$ minute was set as a standard condition. In this study, the thermal behaviors of the irradiated horseshoe crab chitosan $(\mathrm{HCH})$ were analyzed from the TG/DTA curves within the temperature range of $50-650^{\circ} \mathrm{C}$. At the initial 
time, the weight of the $\mathrm{HCH}$ was around $5.4 \mathrm{mg}$. TG/DTA was implemented to measure the change in weight of the sample when it was subjected to an isothermal temperature changed in a controlled way. On the other hand, chitosan comprised of different molecular weights (post- $\gamma$-irradiation) was placed onto a carbon tape and plated with gold using the sputter coater (POLARON-SC7620, Carbon Accessory, and Model-CA76, Quorum Technologies Ltd., Laughton, East Sussex, UK), before being observed through a scanning electron microscope (Carl Zeiss SMT, Oberkochen, Germany) operating at an accelerated voltage of $20 \mathrm{kV}$ at a $4.0 \mathrm{kx}$ magnification.

\subsection{Antioxidant Activity}

\subsubsection{DPPH Radical Scavenging Activity}

The effect of $\gamma$-irradiated chitosan on DPPH radicals was investigated, using the modified method of the previous study [30]. Briefly, $100 \mu \mathrm{M}$ stock was prepared by adding $39.4 \mathrm{mg}$ DPPH(2,2-diphenyl-1-picrylhydrazyl) to $100 \mu \mathrm{L}$ methanol and $1.0 \mathrm{~mL}$ of this solution was added to $4.0 \mathrm{~mL}$ test sample solution containing different concentrations of chitosan. The reaction mixture was shaken properly for $30 \mathrm{~min}$ in an incubation chamber at $37^{\circ} \mathrm{C}$ and the absorbance of the resulting solution was measured at $517 \mathrm{~nm}$ to determine the final concentration. The DPPH scavenging activity of chitosan was calculated according to the following equation:

$$
\text { DPPH Scavenging }(\%)=\left(1-\left(\frac{\text { A samples } 517 \mathrm{~nm}}{\text { A control }}\right)\right) \times 100 \text {. }
$$

\subsubsection{Superoxide Anion Radical Scavenging Assay}

Chitosan was prepared in $0.2,1.0,2.0,10$, and $20 \mathrm{mg} / \mathrm{mL}$ aliquots as a control group. Conversely, $100 \mathrm{mM}$ phosphate buffer ( $\mathrm{pH}$ 7.4) was prepared, before $1 \mathrm{~mL}$ of this solution was added to $4 \mathrm{~mL}$ horseshoe crab chitosan stock and the control solutions. Then, $50 \mu \mathrm{L}$ of each chitosan solution was added to $50 \mu \mathrm{L}$ of $300 \mu \mathrm{M}$ nitro blue tetrazolium (NBT), $50 \mu \mathrm{L}$ of $936 \mu \mathrm{M} \beta$-Nicotinamide Adenine Dinucleotide (NADH), and $50 \mu \mathrm{L}$ of $120 \mu \mathrm{M}$ phenazine methosulfate, before being incubated at room temperature for $5 \mathrm{~min}$. It proceeded with an absorbance reading using a spectrophotometer set at a $560 \mathrm{~nm}$ wavelength. The scavenging capacity of the superoxide radical was estimated using adaptations of Robak and Gryglewski [31] by the following Equation (3).

$$
\text { Superoxide Scavenging }(\%)=\left(1-\left(\frac{\mathrm{A} \text { samples } 517 \mathrm{~nm}}{\mathrm{~A} \text { control }}\right)\right) \times 100
$$

\subsubsection{Metal Ion Chelating Assay}

The ferrous ion-chelating activity assay was conducted by adopting the method of Yen et al. [32], using spectrophotometer analysis at a $562 \mathrm{~nm}$ wavelength. The reaction mixture containing chitosan was added to $2 \mathrm{mM} \mathrm{FeCl}_{2}$ and $5 \mathrm{mM}$ ferrozine, before being incubated for $10 \mathrm{~min}$ at room temperature. The EDTA was used as the positive control and the capacity of sulfated chitosan to chelate ferrous ions was calculated using the following Equation (4):

$$
\text { Chelating Effect }(\%)=\left(1-\left(\frac{\text { A samples } 517 \mathrm{~nm}}{\text { A control }}\right)\right) \times 100 \text {. }
$$

\subsubsection{Total Reducing Power Ability}

In the preparation of chitosan stock solutions, the aliquots of 1.0,1.2, 1.4, 1.6, and $2.0 \mathrm{mg} / \mathrm{mL}$ were dissolved in $1 \%$ glacial acetic acid. The control was prepared using $1 \%$ glacial acetic acid solution as stock. All of the stock solutions were added to $0.5 \mathrm{~mL} 1 \%$ potassium ferricyanide in $0.5 \%$ acetic acid solution, before the addition of $0.2 \mathrm{M}$ sodium phosphate buffer ( $\mathrm{pH}$ 6.6) into a final volume 
of $1.5 \mathrm{~mL}$. The reaction mixtures were incubated at $50{ }^{\circ} \mathrm{C}$ for $20 \mathrm{~min}$. Subsequently, $0.5 \mathrm{~mL}$ of $10 \%$ trichloroacetic acid (TCA), $2 \mathrm{~mL}$ of distilled water, and $400 \mu \mathrm{L}$ of $0.1 \%$ of ferric chloride were added into the mixtures, before centrifuging them at $3000 \mathrm{rpm}$ for $10 \mathrm{~min}$, and the absorbance was measured at $700 \mathrm{~nm}$. An estimation of reducing the ability for chitosan was carried out by adopting the protocols of Oyaizu by following Equation (5) [33].

$$
\text { Reducing Ability }(\%)=\left(1-\left(\frac{\text { A samples } 517 \mathrm{~nm}}{\text { A control }}\right)\right) \times 100
$$

\subsection{Statistical Analysis}

Descriptive statistics (mean and standard deviation) and one-way analysis of variance (ANOVA) employed in SPSS v.17 (IBM Corp, Armonk, NY, USA) were used to evaluate the antioxidant ability of irradiated and non-irradiated horseshoe crab chitosan.

\section{Results and Discussion}

\subsection{Production of Low Molecular Weight Chitosan}

The intrinsic viscosity and molecular weight of non-irradiated chitosan were $144.7 \mathrm{~cm}^{3} / \mathrm{g}$ and $187,128.42 \mathrm{gmol}^{-1}$, respectively. However, irradiation caused a significant decrease in both the intrinsic viscosity and molecular weight of the chitosan. Figure 1a shows the decrease in the intrinsic viscosity of chitosan when applied with an irradiation dosage of 10 and $20 \mathrm{kGy}$. A direct relationship between the increase of the irradiation dose and the decrease of $M_{W}$ can be observed in Figure 1b. Usually, $\gamma$-exposure caused a scission reaction along with the 1-4 glycosidic bonds, which facilitated chitosan degradation and consequently reduced its molecular weight [6]. Probably, the break of the polymer chains is the prevailing process that occurred during the exposure of the polymer to the $\gamma$-ray, which also occurs when radiation is applied to marine-organism chitosan [34]. Moreover, the irradiation induces a depolymerization reaction that causes the scission of the molecule, which is prominent in smaller chitosan chains $[35,36]$.

An identical approach was used in food preservation so that lower molecular weight chitosan (after $\gamma$-irradiation) promoted anti-oxidant activity [25]. However, industrial applications limit ${ }^{60} \mathrm{Co}$ irradiation to a dose-dependent rate of $10 \mathrm{kGy} / \mathrm{h}$, with a maximum dose of $50 \mathrm{kGy} / \mathrm{h}$ [25]. With reference to the $20 \mathrm{kGy}$ doses of $\gamma$-irradiation used in the present study, both the covalent bond strength and chemical structure influenced the compaction and molecular weight of chitosan. In this case, the use of chitosan from horseshoe crabs indefinitely reduced the industrial costs, without compromising functional groups, when intended for food preservation.

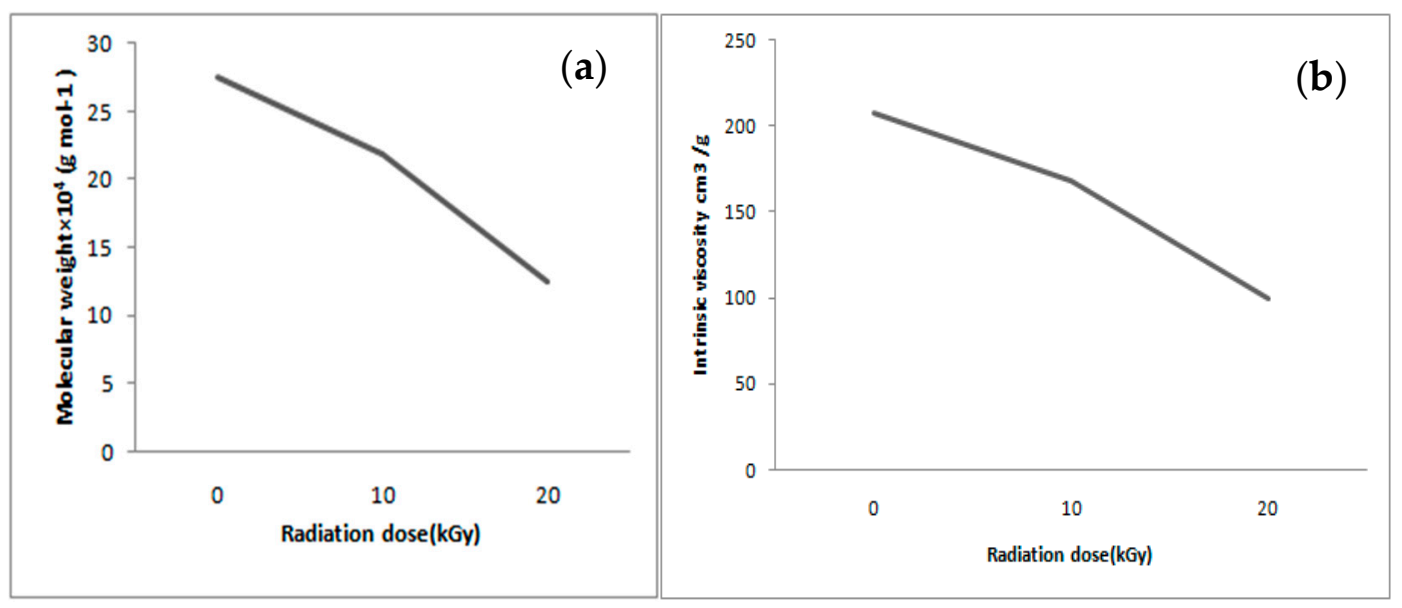

Figure 1. Effect of gamma radiation on the (a) Intrinsic viscosity and (b) molecular weight of chitosan. 


\subsection{Characterization of Horseshoe Crab Chitosan}

The degree of horseshoe crab chitosan deacetylation pertains to the quantity of glucosamine within the biopolymer chains during the transition of chitosan from chitin. While the bands 1221 and $1505 \mathrm{~cm}^{-1}$ were adopted as a reference and non-irradiated chitosan produced an $83.90 \%$ degree of deacetylation, whereas for 10 and $20 \mathrm{kGy}$ irradiated chitosan, the value was $85 \%$ and $86 \%$, respectively. Taking into account the reduced molecular weight of chitosan and the inversely increasing degree of deacetylation after irradiation, altering the chitosan crystallinity and viscosity amounts to degradation [31] that favors its use in the food industry [25]. The availability of low molecular weight chitosan favors the manufacturing of low viscosity liquids and omits the need for demineralization processes (reducing the manufacturing costs). Considering the intrinsic viscosity, for irradiated chitosan at 10 and $20 \mathrm{kGy}$, the valueswere 160.00 and $98.80 \mathrm{cP}$, respectively, which are associated with a low range of viscosity if compared to industrial paramount $[30,31,37,38]$.

Hydroxyl (-OH) stretching bands of horseshoe crab chitosan were $3435.81 \mathrm{~cm}^{-1}$ and, for the $\mathrm{C}-\mathrm{H}$ group, they were 2995 and $2988.94 \mathrm{~cm}^{-1}$ after the 10 and $20 \mathrm{kGy}$ irradiation, respectively (Figure 2).

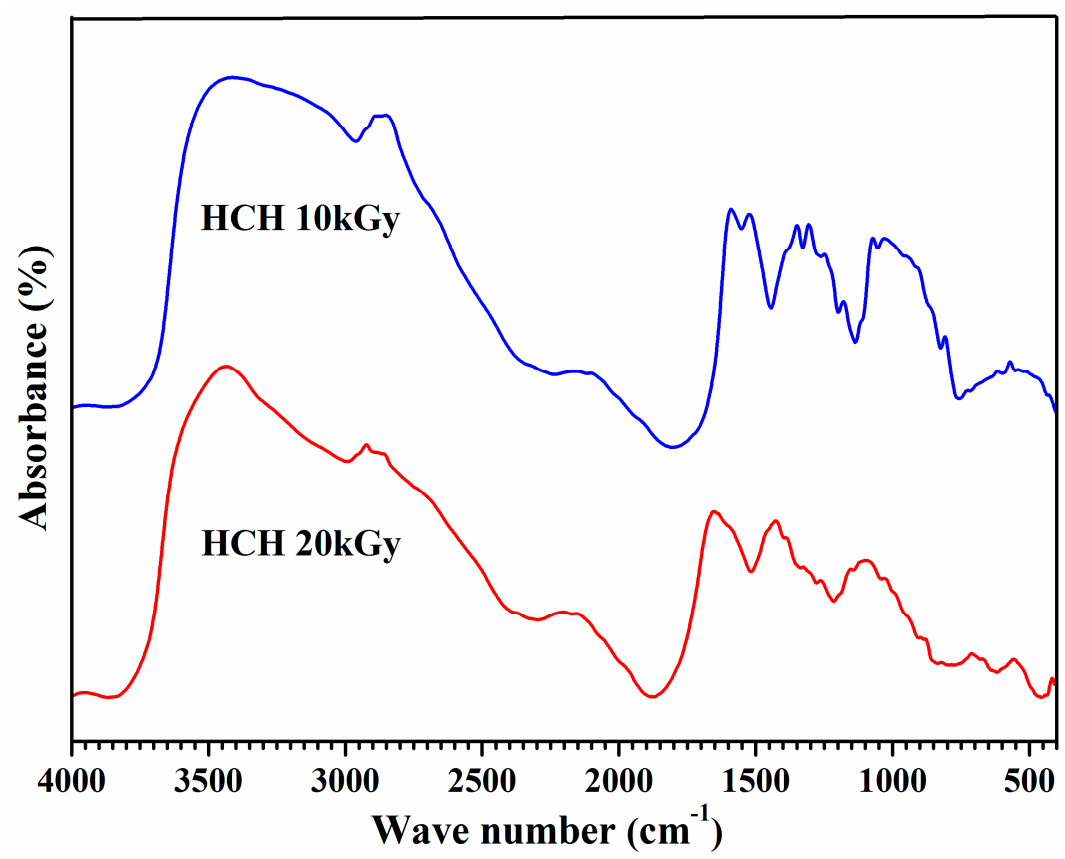

Figure 2. Fourier transfer infrared (FTIR) spectra of horseshoe crab chitosan $(\mathrm{HCH})$ irradiated at 10 and $20 \mathrm{kGy}$.

Chitosan's C $=\mathrm{O}$ stretching band (pyranose ring) was $1878 \mathrm{~cm}^{-1}$, its $\mathrm{NH}$ group stretching bands occurred at $1512.65 \mathrm{~cm}^{-1}$, and the NHCO amine complexes produced bands of 1221 and 1214.20 $\mathrm{cm}^{-1}$. While identical stretch bands were also retrieved in past findings [39], conformities to identical samples suggest that irradiation up to $20 \mathrm{kGy}$ through a ${ }^{60} \mathrm{Co}$ source breaks double bonds to reduce the molecular weight of horseshoe crab chitosan. However, $-\mathrm{NH}$ groups were less affected by the $\gamma$-irradiation (decreased FTIR transmittance band) and appeared to have a close resemblance to non-irradiated chitosan [12]. Again, chitosan sources were crucial, particularly for obtaining the optimal degree of deacetylation after $\gamma$-irradiation, because it was $75 \%$ for the present study and much lower for non-arthropod sources [40].

Peculiarly, XRD patterns for $10 \mathrm{kGy} \gamma$-ray-irradiated chitosan peaks at $2 \theta=10.5^{\circ}, 20.04^{\circ}$, and $21.9^{\circ}$ with reflections were 20, 200, and $220 \mathrm{~h}$, respectively. (Figure 3), which was identical to non-irradiated chitosan [12-31]. However, when the $20 \mathrm{kGy} \gamma$-ray was used, an additional peak developed at $2 \theta$ $=10.5^{\circ}$. This was an indication that increased $\gamma$-irradiation splits the peak at $2 \theta=10.5^{\circ}$ into two separate attributes because of chitosan crystalline structure manipulation. When thermal manifestation 
(50 to $650^{\circ} \mathrm{C}$ ) was applied to chitosan after $\gamma$-irradiation, it was discovered that degradation and decomposition occurred first, before the residue remained (Figure 4). In this sense, heating chitosan at $100{ }^{\circ} \mathrm{C}$ causes water evaporation and proceeds with endothermic dehydration [41].

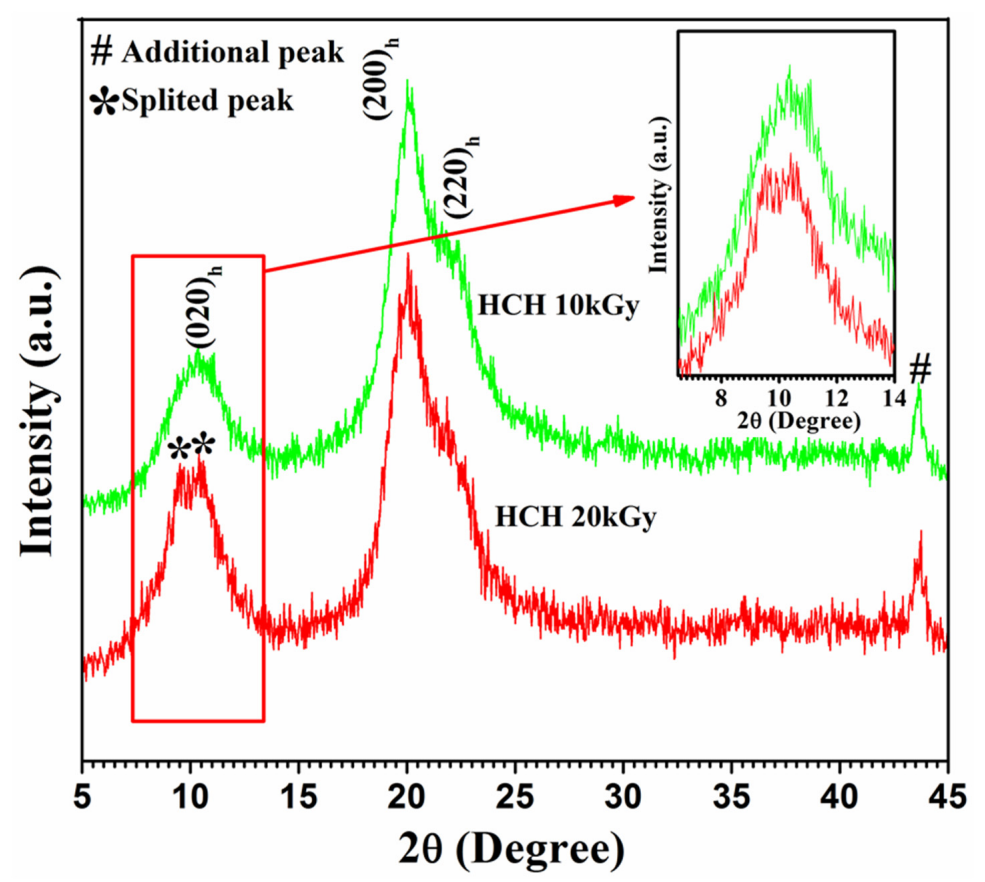

Figure 3. X-ray diffraction (XRD) patterns of $\mathrm{HCH}$ irradiated at 10 and $20 \mathrm{kGy}$.

Moreover, heat exposure between 100 to $150{ }^{\circ}$ Ccaused thermal degradation and complete evaporation before depolymerization when the temperature reached $270{ }^{\circ} \mathrm{C}$ (Figure $4 \mathrm{a}, \mathrm{b}$ ). The $60 \%$ weight loss of chitosan at $300^{\circ} \mathrm{C}$ (optimal decomposition temperature range of 303-306 ${ }^{\circ} \mathrm{C}$ ) indicates that amino polymers were less stable than $\mathrm{N}$-acyl bonds. The effects of $\gamma$-irradiation on altering the chitosan crystalline structure wore out during degradation when chitosan was exposed to a temperature of $430{ }^{\circ} \mathrm{C}$. Since irradiated chitosan has better thermal stability than non-irradiated chitosan [12], the present findings suggest that $\mathrm{N}$-acyl bonds were reinforced with the 10 and $20 \mathrm{kGy} \gamma$-irradiation.

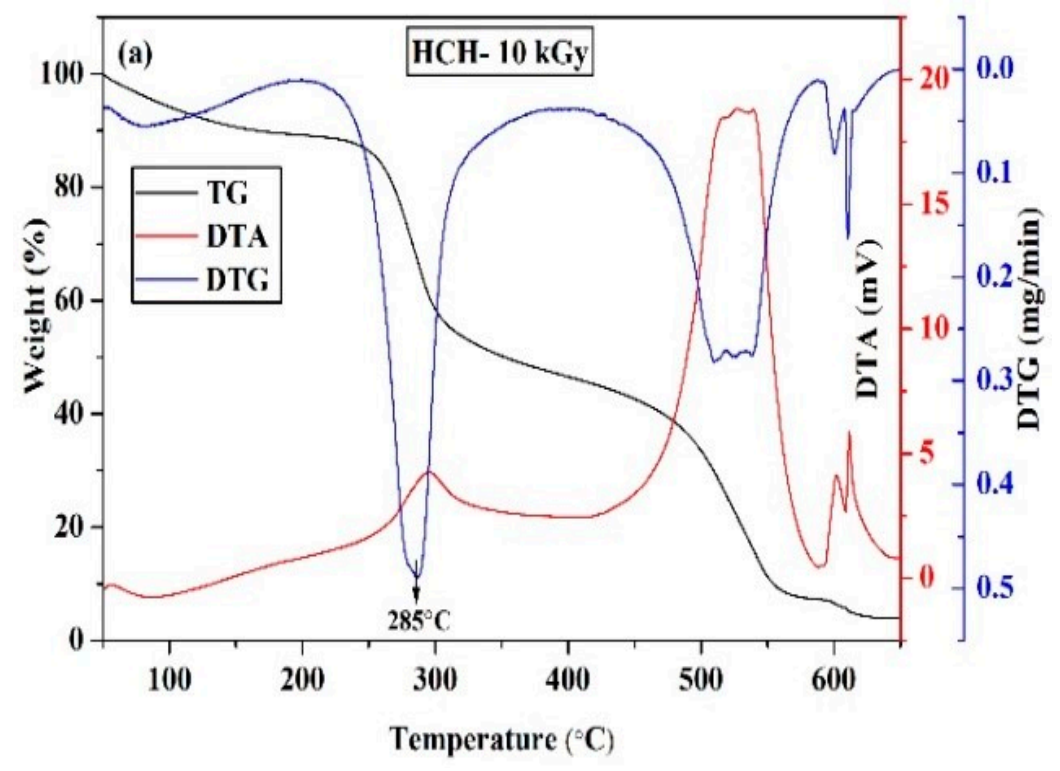

Figure 4. Cont. 


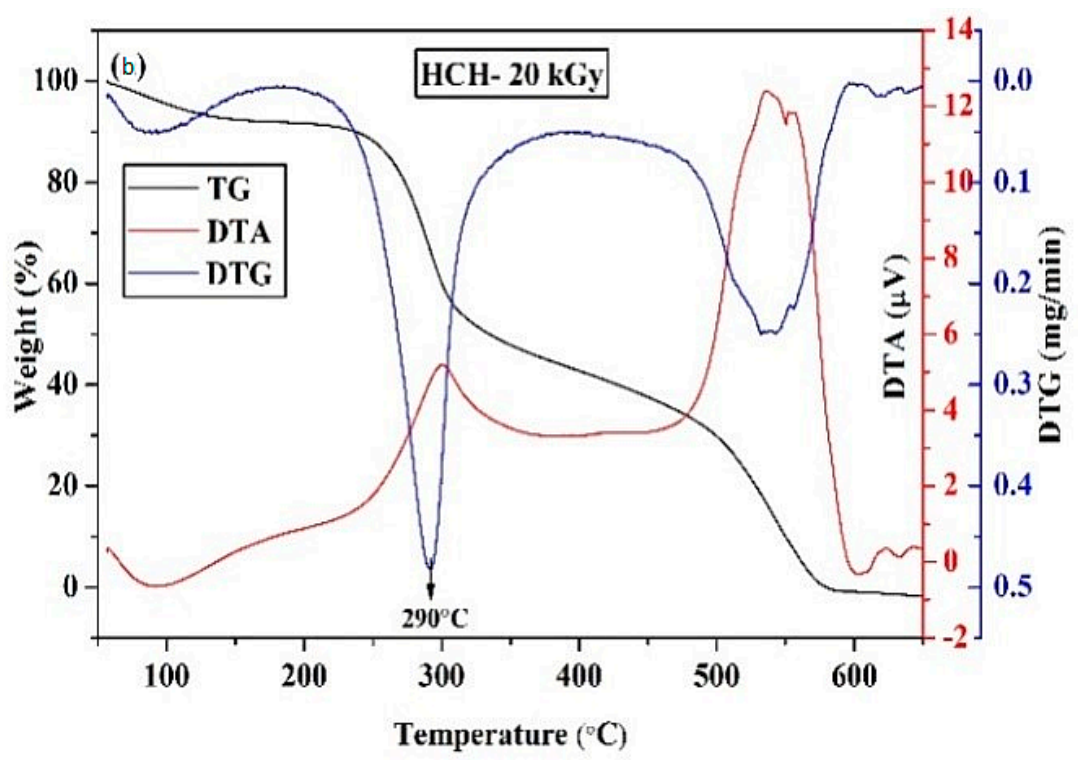

Figure 4. Thermogravimetry (TG), DTG, and differential thermal analysis (DTA) curves of irradiated chitosan: (a)HCH-10 kGy and (b) HCH-20 kGy.

The SEM micrographs of the irradiated chitosan surface (Figure $5 a, b)$ indicated folding and layering, while non-irradiated chitosan has a fiber-like surface [12]. The difference in the morphological appearance of the irradiated and non-irradiated chitosan might be attributed to the breaking of bonds during irradiation.

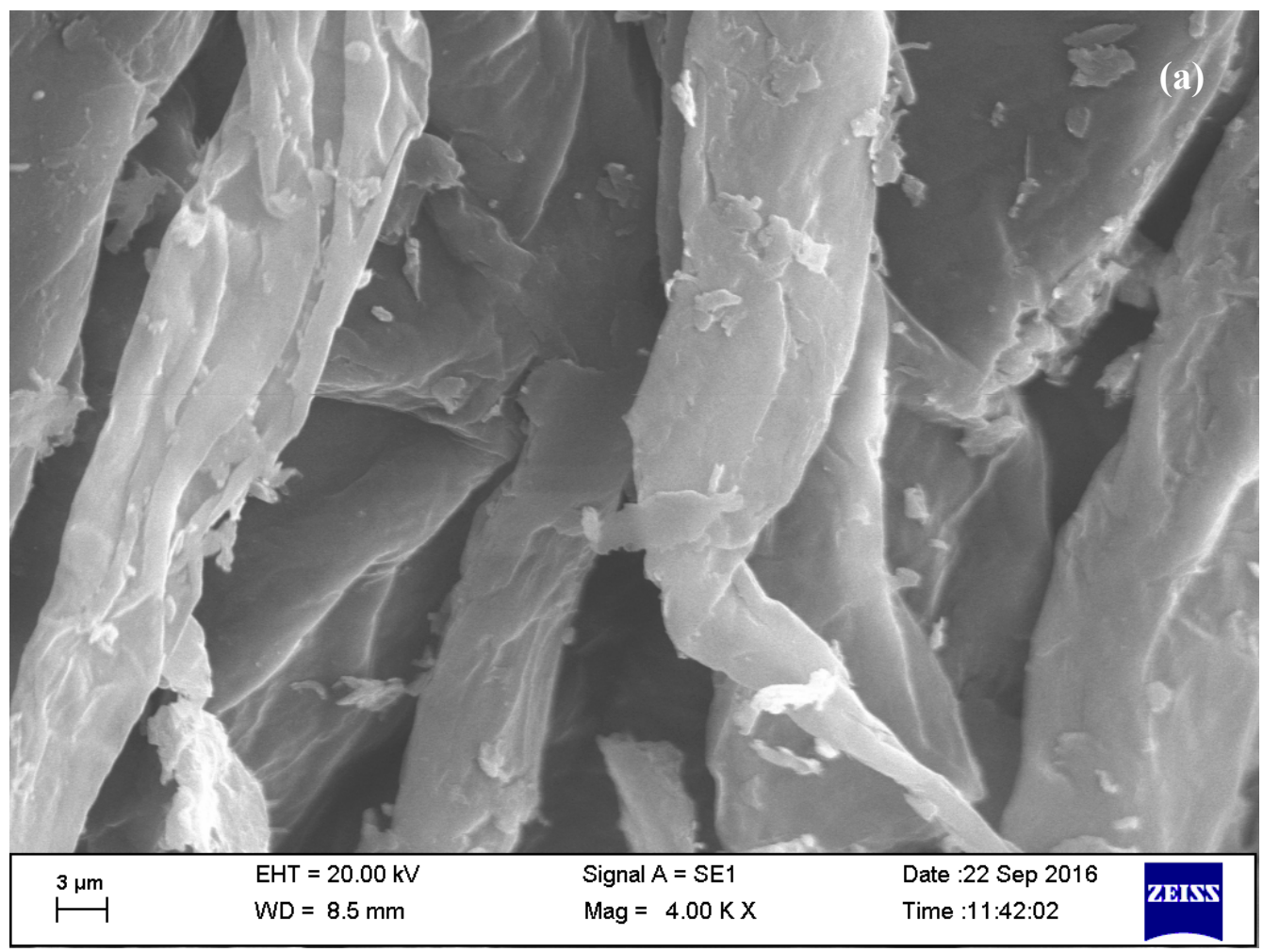

Figure 5. Cont. 


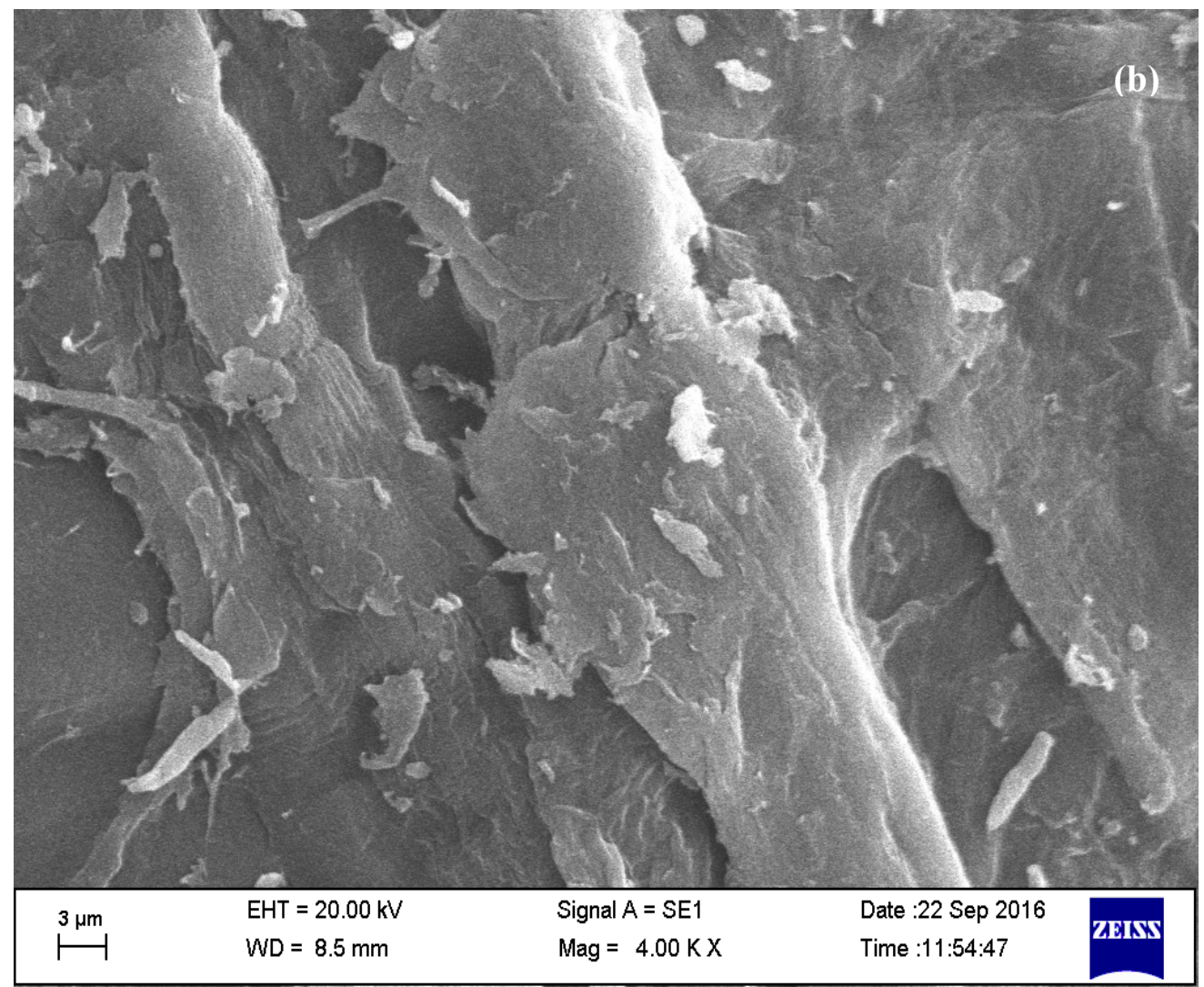

Figure 5. SEM micrographs of irradiated chitosan: (a) HCH-10 kGy and (b) HCH-20 kGy.

\subsection{Antioxidant Activity}

After exposure to DPPH, the superoxide radical scavenging ability followed the order of ascorbic acid $(45.48 \pm 1.05 \%)>20 \mathrm{kGy}(39.95 \pm 1.43 \%)>10 \mathrm{kGy}(31.86 \pm 1.09 \%)>0 \mathrm{kGy}(23.21 \pm 0.62 \%)$ (Figure 6a), with chitosan exhibiting some antioxidant ability. A 37.33\% (for $10 \mathrm{kGy}$ ) and $72.12 \%$ (20 $\mathrm{kGy}$ ) increase was witnessed for DPPH activity with respect to the untreated sample (0 kGy). It has been reported that the antioxidant activity of chitosan increases with the increase of irradiation doses and decreases the $M_{W}$ [21]. It was reported that one of the mechanisms of chitosan is related to its scavenging activity, which can respond with free radical leftover free $-\mathrm{NH}_{2}$ groups to form stable molecules and the $-\mathrm{NH}_{2}$ groups can form ammonium groups $\left(\mathrm{NH}_{3}^{+}\right)$by capturing a hydronium ion from the solution [32].

The reconfigured horseshoe crab chitosan can be functionalized to reduce oxidative stress, as well as employed externally for scald-wound healing [42-45]. An identical trend was also achieved for the superoxide anion scavenging activity (Figure 6b); however, the margin of differences for this activity was small, as indicated by the ascorbic acid $(83.42 \pm 0.03 \mathrm{mg} / \mathrm{mL})$ and $20 \mathrm{kGy}(80.26 \pm 0.02 \mathrm{mg} / \mathrm{mL})$ exposures to chitosan. Only a $3.93 \%$ enhancement in the superoxide anion scavenging activity was observed for the $20 \mathrm{kGy}$ irradiated product. On the contrary to DPPH, superoxide radicals are naturally generated reactive oxygen species within the cell matrix, so the superoxide anion scavenging activity actually mimics the actual condition within the human body and is thus able to give an overview of how the product will act in an in-vivo condition [31]. Comparatively, fungal chitosan displayed a radical scavenging ability of $2.84-5.35 \%$ [38], whereas for Shiitake stipes and crab shell, it was lower, at $2.84 \%[46,47]$, if compared to Portunus pelagicus and Podophthalmus vigil crab shell, which showed $4.64-5.23 \%$ [38] and 5.56\% values for their chitosan [48].

Horseshoe crab chitosan appeared to be more than 40 times more effective than marine crab shells, and the addition of $\mathrm{NaOH}$ during $\mathrm{N}$-deacetylation enhanced its radical scavenging ability. While the 
radical scavenging ability was inversely correlated with the chitosan molecular weight, the hydroxyl and amine groups in the chitosan molecule were responsible for the radical scavenging activities. Therefore, more highly deacetylated chitosan would have higher radical scavenging activities $[48,49]$. Unfortunately, acidic conditions (EDTA) made the amine groups of horseshoe crab chitosan inert and less effective for anti-oxidant activity. Despite this, chitosan with a reduced degree of acetylation has its amino acid readily available for metal adsorption [50]. When tested independently, EDTA effectively chelates ferrous ions $(94.62 \pm 0.02 \%)$ [51]. However, decreasing the molecular weight of horseshoe crab chitosan after $0 \mathrm{kGy}(14.16 \pm 0.03 \%), 10 \mathrm{kGy}(21.35 \pm 0.04 \%)$, and $20 \mathrm{kGy}(28.43 \pm 0.02 \%) \gamma$-exposure (Figure $6 \mathrm{c}$ ) showed increasing activity against radical scavenging. A $50.77 \%$ - and $1.07 \%$-fold increase in the ferrous ion chelating activity was recorded for the 10 and $20 \mathrm{kGy}$ irradiated products, respectively.
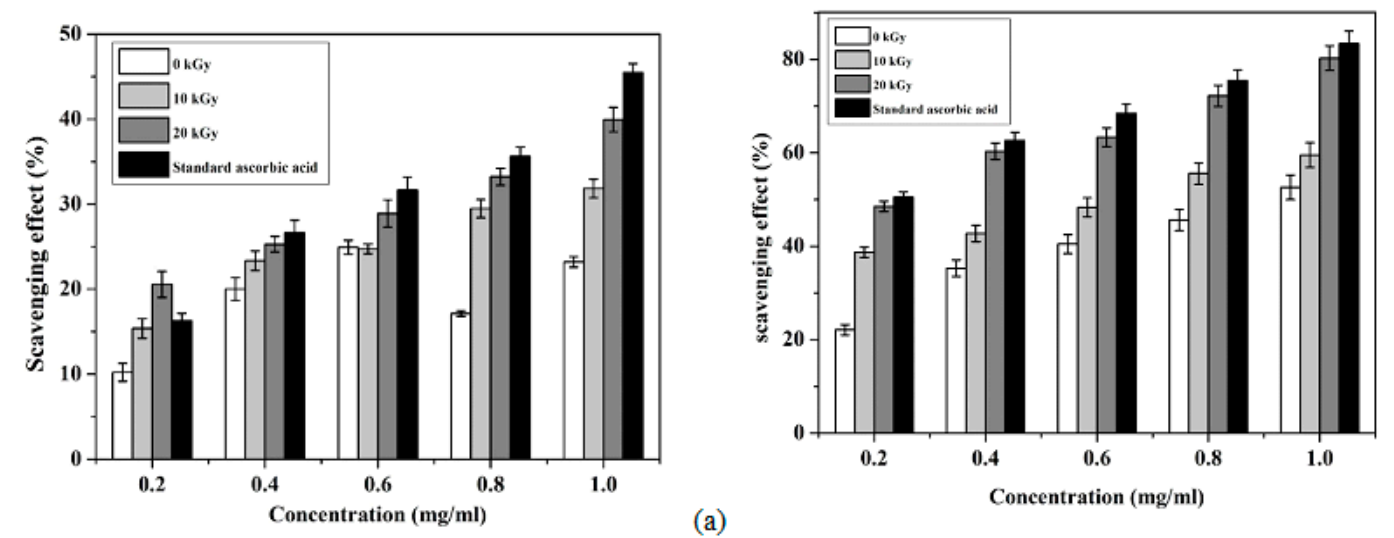

(a)
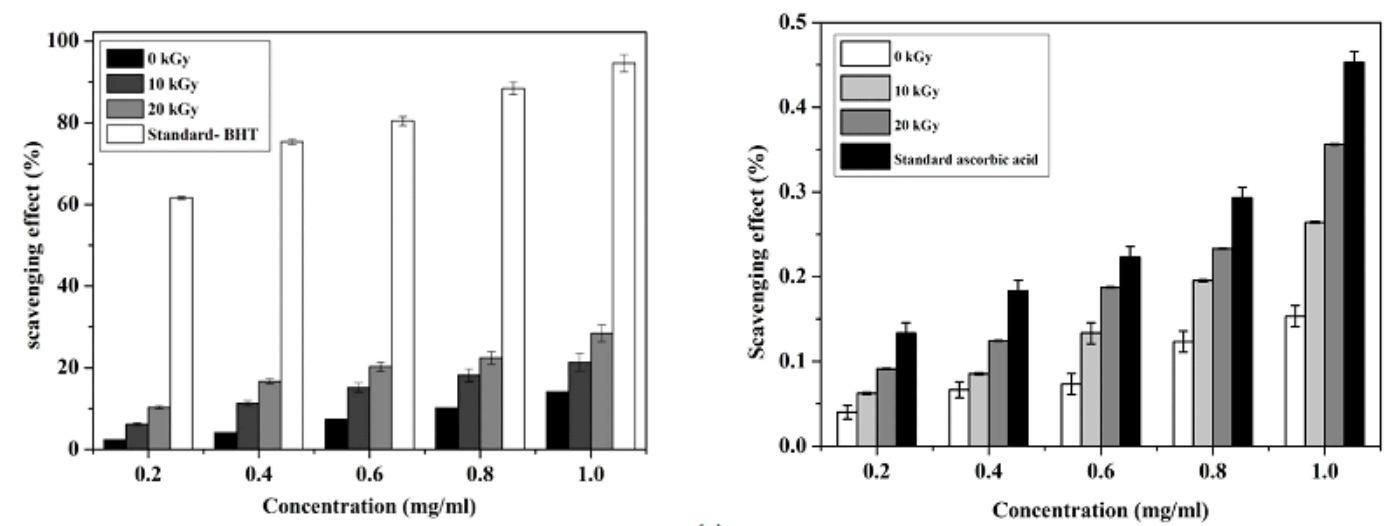

(c)

(d)

Figure 6. Antioxidant activity of horseshoe crab chitosan after different irradiation exposure. (a) Scavenging effects of horseshoe crab chitosan with different doses and ascorbic acid on DPPH radicals. Each value is presented as the mean $\pm \operatorname{SE}(n=3)$ and values were significantly different at $p<0.05$. (b) Scavenging effects of horseshoe crab chitosan with different doses (DDC) and ascorbic acid on superoxide anion radicals. Each value represents the mean $\pm \mathrm{SE}(n=3)$ and values were significantly different at $p<0.05$. (c) Chelating effects of horseshoe crab chitosan with different doses and EDTA on ferrous ions. Each value is presented as the mean \pm SE $(n=3)$ and values were significantly different at $p<0.05$. (d) The total reducing power ability of Butylated hydroxytoluene and the different doses of chitosan from (DDC) horseshoe crab. Data are presented as the mean \pm S.E. $(n=3)$ and were significantly different at $p<0.05$.

Additionally, the ferrous-ion chelation rate was proportional to the concentration of chitosan used, and an identical observation was also seen with fungal chitosan [46]. The molecules of chitosan may act as a chelating ligand at the second and third carbon atoms of the chitosan monomer and form chelates with $\mathrm{Fe}^{2+}$. Irradiation may cause a lower $M_{W}$ compound, which in turn will expose more amine and hydroxyl groups, and these play a pivotal role in determining the ferrous-ion chelation rate. In this 
regard, selection of the $\gamma$-irradiation limit (10-20 kGy) made the horseshoe crab chitosan effective for hydroxyl $(50.47 \pm 0.1 \%)$ and superoxide $(52.65 \pm 0.04 \%-80.26 \pm 0.02 \%)$ radical scavenging if compared with Podophthalmus vigil shell chitosan $(6.25 \%$ and $1.21-7.74 \%$, respectively) [48]. When tested against diethyldithiocarbamate, the order for radical scavenging was butylated hydroxytoluene $(0.46 \pm 0.01 \%)>20 \mathrm{kGy}(0.36 \pm 0.001 \%)>10 \mathrm{kGy}(0.26 \pm 0.001 \%)>0 \mathrm{kGy}(0.15 \pm 0.01 \%)$ (Figure $6 \mathrm{~d})$. Therefore, from the results, it is obvious that there is a 2.40- and 1.73-fold increase in the total reducing power of the chitosan produced at 20 and $10 \mathrm{kGy}$, respectively, in comparison to the sample unexposed to any radiation. Our findings clearly showed that the antioxidant property of horseshoe crab chitosan was inversely related to its molecular weight. This might be due to the chitosan with larger $M_{W}$ having a more compact structure, which results in stronger intramolecular hydrogen bonds and restricts the hydroxyl and amine groups from reacting with radicals or metal ions. Conversely, the horseshoe crab chitosan reaction rate against free radicals increases with the $\gamma$-irradiation and dosage concentration; however, it also has an overdose limit that should not exceed the 1:1 w/w ratio. While chitosan from horseshoe crab carapace may seem beneficial to the biomedical industry due to its negligible use in India, this is not the situation in other Asian countries, where T. gigas was discovered [52-56], and another form of chitosan that originates from Orthoptera (Calliptamus barbarous and Oedaleus decorus) was proposed [57]. Regarding this, chitin and chitosan extraction from invasive or pest species may be useful for controlling over-breeding populations because their bioactive compounds are replenishable (large population size) and reducing production costs in food manufacturing industries. The vast number of abandoned carapaces usually causes environmental issues and marine ecology pollution. Alternatively, this waste can be used as an economic source of chitosan and its derivatives. The characteristics of the horseshoe crab chitosan produced in our study were according to the commercial standard.

\section{Conclusions}

The horseshoe crab chitosan powder samples $(\mathrm{HCH})$ were successfully subjected to the $\gamma$-irradiation of 10 and $20 \mathrm{kGy}$ doses using a ${ }^{60} \mathrm{Co}$ source. The $\gamma$-irradiated chitosan powder samples were characterized by FTIR, XRD, SEM, and TG/DTA and underwent a change in structure at different doses, with a reduction of the molecular weight. The antioxidant activity of horseshoe crab chitosan was compared for irradiated and non-irradiated forms when applied against antioxidizing agents, such as DPPH, superoxide anions, ferrous ions, and diethyldithiocarbamate. While horseshoe crab chitosan was reconfigured using $\gamma$-exposure, it reduced in molecular weight and appeared with active amino acid groups. The addition of $\mathrm{NaOH}$ increased the rate of chitosan deacetylation, which is an important criterion for enhancing irradiated chitosan's ability against radicals.

Author Contributions: S.P. and B.R.N. designed and performed the experiments and participated in the interpretation of the results and the writing of the paper. T.S., S.S., H.A.E., T.S.B.A.M., P.J., Y.K.M., and D.A. interpreted the results and edited the manuscript. A.C. and B.P.D. supervised and discussed the research and edited the manuscript. All the authors contributed to the realization of the manuscript. All authors have read and agreed to the published version of the manuscript.

Funding: This research was funded by Board of Research in Nuclear Sciences, (BRNS), Department of Atomic Energy (DAE), Govt of India, Sanction number 2012/35/26/BRNS. The APC was jointly supported by University Malaysia Terengganu and University Sains Malaysia.

Acknowledgments: The authors gratefully acknowledge the support provided by the Institute of Tropical Biodiversity and Sustainable Development, University Malaysia Terengganu to prepare this manuscript. The authors especially thank Sweetie Kanatt, Siba Prasad Adhikary and Abubacker Aliyamveetil Zynudheen for moral support and encouragement.

Conflicts of Interest: The authors declare no conflict of interest. 


\section{References}

1. Shirai, K.; Guerrero, I.; Huerta, S.; Saucedo, G.; Casillo, A.; Gonzalez, R.O.; Hall, G.M. Effect of initial glucose concentration and inoculation level of lactic acid bacteria in shrimp waste ensilation. Enzym. Microb. Technol. 2001, 28, 446-452. [CrossRef]

2. Xu, Y.; Gallert, C.; Winter, J. Chitin purification from shrimp wastes by microbial deproteination and decalcification. Appl. Microbiol. Biotechnol. 2008, 79, 687-697. [CrossRef] [PubMed]

3. Aytekin, O.; Elibol, M. Cocultivation of Lactococcuslactis and Teredinobacterturnirae for biological chitin extraction from prawn waste. Bioprocess. Biosyst. Eng. 2010, 33, 393-399. [CrossRef]

4. Bautista, J.; Jover, M.; Guttierrez, J.F.; Corpas, R.; Cremades, O.; Fontiveros, E. Preparation of crayfish chitin by in situ lactic acid production. Process. Biochem. 2001, 37, 229-234. [CrossRef]

5. Rinaudo, M. Chitin and chitosan: Properties and applications. Prog. Polym. Sci. 2006, 31, 603-632. [CrossRef]

6. Zhao, Y.; Park, R.D.; Muzzarelli, R.A. Chitin deacetylases: Properties and applications. Mar. Drugs 2010, 8, 24-46. [CrossRef] [PubMed]

7. Synowiecki, J.; Al-Khateeb, N.A. Production, properties, and some new applications of chitin and its derivatives. Crit. Rev. Food Sci. Nutr. 2003, 43, 145-171. [CrossRef] [PubMed]

8. Dutta, P.K.; Ravikumar, M.N.V.; Dutta, J. Chitin and chitosan for versatile applications. J. Macromol. Sci.Part C Polym. Rev. 2002, 42, 307-354. [CrossRef]

9. Bautista-Baños, S.; Hernández-Lauzardo, A.N.; Velázquez del Valle, M.G.; HernándezLópez, M.; AitBarka, E.; BosquezMolina, E.; Wilson, C.L. Chitosan as a potential natural compound to control pre and postharvest diseases of horticultural commodities. Crop. Prot. 2006, 25, 108-118. [CrossRef]

10. Brzeski, M.M. Chitin and chitosan putting waste to good use. Infofish Int. 1987, 5, 31-33.

11. Muzzarelli, R.A. Chitin and its derivatives: New trends of applied research. Carbohydr. Polym. 1983, 3, 53-75. [CrossRef]

12. Pati, S.; Chatterji, A.; Dash, B.P. Chitosan from the carapace of Indian horseshoe crab (Tachypleusgigas, müller): Isolation and its characterization. Adv. Biores. 2016, 9, 52-64.

13. Raafat, D.; Sahl, H.G. Chitosan and its antimicrobial potential-A critical literature survey. Microb. Biotechnol. 2009, 21, 86-201. [CrossRef]

14. Helander, I.M.; Nurmiaho-Lassila, E.L.; Ahvenainen, R.; Rhoades, J.; Roller, S. Chitosan disrupts the barrier properties of the outer membrane of Gram-negative bacteria. Int. J. Food Microbiol. 2001, 71, $235-244$. [CrossRef]

15. Nagamaniammai, G.; Chithra, M.; Udhaya Ganga, M. Study on the Effect of Prawn (Machrobrachuimrosenbergii) Chitosan Coating on Peeled Shallot (Allium ascalonicum). Curr. Res. Nutr. Food Sci. 2019, 7,927-935. [CrossRef]

16. Mao, S.; Shuai, X.; Unger, F.; Simon, M.; Bi, D.; Kissel, T. The depolymerization of chitosan: Effects on physicochemical and biological properties. Int. J. Pharm. 2004, 281, 45-54. [CrossRef] [PubMed]

17. Wasikiewicz, J.M.; Yoshii, F.; Nagasawa, N.; Wach, R.A.; Mitomo, H. Degradation of chitosan and sodium alginate by $\gamma$-radiation, sonochemical and ultraviolet methods. Radiat. Phys. Chem. 2005, 73, $287-295$. [CrossRef]

18. Chmielewski, A.G. Chitosan and radiation chemistry. Radiat. Phys. Chem. 2010, 79, 272-275. [CrossRef]

19. Ciechanska, D. Multifunctional bacterial cellulose/chitosan composite materials for medical applications. Fibres Text. East. Eur. 2004, 12, 69-72.

20. Lopez-Mata, M.A.; Ruiz-Cruz, S.; Silva-Beltran, N.P.; Ornelas-Paz, J.D.; Zamudio-Flores, P.B.; Burruel-Ibarra, S.E. Physicochemical, antimicrobial and antioxidant properties of chitosan films incorporated with carvacrol. Molecules 2013, 18, 13735-13753. [CrossRef] [PubMed]

21. Avelelas, F.; Horta, A.; Pinto, L.F.V.; Cotrim Marques, S.; Marques Nunes, P.; Pedrosa, R.; Leandro, S.M. Antifungal and antioxidant properties of chitosan polymers obtained from nontraditional Polybius henslowii sources. Mar. Drugs 2019, 17, 239. [CrossRef]

22. Kim, K.W.; Thomas, R.L. Antioxidative activity of chitosan with varying molecular weights. Food Chem. 2007, 101, 308-313. [CrossRef]

23. Tikhonov, V.E.; Stepnova, E.A.; Babak, V.G.; Yamskov, I.A.; Palma-Guerrero, J.; Jansson, H.B. Bactericidal and antifungal activities of a low molecular weight chitosan and its N-/2(3)-(dodec-2-enyl)succinoyl/-derivatives. Carbohydr. Polym. 2006, 64, 66-72. [CrossRef] 
24. Gryczka, U.; Gawronska, H.; Migdał, W.; Gawronski, S.W.; Chmielewski, A.G. Study on biological activity of chitosan after radiation processing. Nukleonika 2008, 53, S73-S76.

25. Pati, S.; Jena, P.; Shahimi, S.; Nelson, B.R.; Acharya, D.; Dash, B.P.; Chatterji, A. Characterization dataset for pre-and post-irradiated shrimp waste chitosan. Data Brief 2020, 32, 106081. [CrossRef] [PubMed]

26. Rinaudo, M.; Milas, M.; Le Dung, P. Characterization of chitosan. Influence of ionic strength and degree of acetylation on chain expansion. Int. J. Biol. Macromol. 1993, 15, 281-285. [CrossRef]

27. Zhang, D.; Yang, S.; Chen, Y.; Liu, S.; Zhao, H.; Gu, J. 60Co $\gamma$-ray Irradiation Crosslinking of Chitosan/Graphene Oxide Composite Film: Swelling, Thermal Stability, Mechanical, and Antibacterial Properties. Polymers 2018, 10, 294. [CrossRef]

28. Domszy, J.G.; Roberts, G.A. Evaluation of infrared spectroscopic techniques for analysing chitosan. Makromol. Chem. Macromol. Chem. Phys. 1985, 186, 1671-1677. [CrossRef]

29. Fernandez-Kim, S.O. Physicochemical and Functional Properties of Crawfish Chitosan as Affected by Different Processing Protocols. Ph.D. Thesis, Seoul National University, Seoul, Korea, 2004.

30. Shimada, K.; Fujikawa, K.; Yahara, K.; Nakamura, T. Antioxidative properties of xanthone on the auto oxidation of soybean in cylcodextrin emulsion. J. Agric. Food Chem. 1992, 40, 945-948. [CrossRef]

31. Robak, J.; Gryglewski, R.J. Flavonoids are scavengers of superoxide, anions. Biochem. Pharmacol. 1988, 36, 317-322.

32. Yen, G.C.; Duh, P.D.; Chuang, D.Y. Antioxidant activity of anthraquinones and anthrone. Food Chem. 2000, 70, 437-441. [CrossRef]

33. Oyaizu, M. Studies on products of browning reaction. Jpn. J. Nutr. Diet. 1986, 44, 307-315. [CrossRef]

34. Yoksan, R.; Akashi, M.; Miyata, M.; Chirachanchai, S. Optimal gamma-ray dose and irradiation conditions for producing low-molecular-weight chitosan that retains its chemical structure. Radiat. Res. 2004, 161, 471-480. [CrossRef]

35. Zainol, I.; Akil, H.M.; Mastor, A. Effect of $\gamma$-irradiation on the physical and mechanical properties of chitosan powder. Mater. Sci. Eng. C 2009, 29, 292-297. [CrossRef]

36. Shen, K.; Hu, Q.; Wang, Z.; Qu, J. Effect of 60Co irradiation on the properties of chitosan rod. Mater. Sci. Eng. C 2011, 31, 866-872. [CrossRef]

37. Taşkın, P.; Canısağ, H.; Şen, M. The effect of degree of deacetylation on the radiation induced degradation of chitosan. Radiat. Phys. Chem. 2014, 94, 236-239. [CrossRef]

38. Yen, M.; Yang, J.; Mau, J. Antioxidant properties of chitosan from crab shells. Carbohydr. Polym. 2008, 74, 840-844. [CrossRef]

39. Clark, G.L.; Smith, A.F. X-ray Diffraction Studies of Chitin, Chitosan, and Derivatives. J. Phys. Chem. 2002, 40, 863-879. [CrossRef]

40. Younes, I.; Ghorbel-Bellaaj, O.; Chaabouni, M.; Rinaudo, M.; Souard, F.; Vanhaverbeke, C.; Jellouli, K.; Nasri, M. Use of a fractional factorial design to study the effects of experimental factors on the chitin deacetylation. Int. J. Biol. Macromol. 2014, 70, 385-390. [CrossRef]

41. Chaiwong, N.; Leelapornpisid, P.; Jantanasakulwong, K.; Rachtanapun, P.; Seesuriyachan, P.; Sakdatorn, V.; Phimolsiripol, Y. Antioxidant and Moisturizing Properties of Carboxymethyl Chitosan with Different Molecular Weights. Polymers 2020, 12, 1445. [CrossRef]

42. Dai, T.; Tanaka, M.; Huang, Y.Y.; Hamblin, M.R. Chitosan preparations for wounds and burns: Antimicrobial and wound-healing effects. Expert Rev. Anti-Infect. Ther. 2011, 9, 857-879. [CrossRef] [PubMed]

43. Liu, H.; Wang, C.; Li, C.; Qin, Y.; Wang, Z.; Yang, F.; Zuhao, L.; Wang, J. A functional chitosan-based hydrogel as a wound dressing and drug delivery system in the treatment of wound healing. RSC Adv. 2018, 8, 7533-7549. [CrossRef]

44. Ahmed, S.; Ikram, S. Chitosan based scaffolds and their applications in wound healing. Achiev. Life Sci. 2016, 10, 27-37. [CrossRef]

45. Pati, S. Isolation of Chitosan from Carapace of Indian Horseshoe Crab (Tachypleusgigas; Müller) and Characterization of Its Antibacterial and Antioxidant Potentials. Ph.D. Thesis, Fakir Mohan University, Odisha, India, 2004.

46. Yen, M.T.; Tseng, Y.H.; Li, R.C.; Mau, J.L. Antioxidant properties of fungal chitosan from shiitake stipes. LWT Food Sci. Technol. 2007, 40, 255-261. [CrossRef]

47. Kuppusamy, S.K.; Karuppaiah, J. Invitro evaluation of free radical scavenging activity of chitosan. Int. J. Pharm. Life Sci. 2013, 4, 2685-2690. 
48. Prabu, K.; Natarajan, E. In vitro antibacterial and antioxidant activity of chitosan isolated from Podophthalmus vigil. J. Appl. Pharm. Sci. 2012, 2, 075-082.

49. Younes, I.; Rinaudo, M. Chitin and chitosan preparation from marine sources. Structure, properties and applications. Mar. Drugs 2015, 13, 1133-1174. [CrossRef]

50. Cheung, R.; Ng, T.; Wong, J.; Chan, W. Chitosan: An update on potential biomedical and pharmaceutical applications. Mar. Drugs 2015, 13, 5156-5186. [CrossRef]

51. Lin, H.Y.; Chou, C.C. Antioxidant activities of water-soluble disaccharide chitosan derivatives. Food Res. Int. 2004, 37, 883-889. [CrossRef]

52. Mat Zauki, N.A.; Satyanarayana, B.; Fairuz-Fozi, N.; Nelson, B.R.; Martin, M.B.; Akbar-John, B.; Chowdhury, A.J.K. Citizen science frontiers horseshoe crab population regain at their spawning beach in East Peninsular Malaysia. J. Environ. Manag. 2019, 232, 1012-1020. [CrossRef]

53. Zauki, N.A.M.; Satyanarayana, B.; Fairuz-Fozi, N.; Nelson, B.R.; Martin, M.B.; Akbar-John, B.; Chowdhury, A.J.K. Horseshoe crab bio-ecological data from Balok, east coast peninsular Malaysia. Data Brief 2019, 22, 458-463. [CrossRef]

54. John, B.A.; Nelson, B.R.; Sheikh, H.I.; Cheung, S.G.; Wardiatno, Y.; Dash, B.P.; Tsuchiya, K.; Iwasaki, Y.; Pati, S. A review on fisheries and conservation status of Asian horseshoe crabs. Biodivers. Conserv. 2018, 27, 3573-3598. [CrossRef]

55. Pati, S.; Tudu, S.; Rajesh, A.; Biswal, G.C.; Chatterji, A.; Dash, B.P.; Samantaray, R. Manmade activities affected the breeding ground of horseshoe crab (Tachypleusgigas) along Balasore coast: Call for immediate conservation. E-Planet 2017, 15, 145-154.

56. Nong, W.; Qu, Z.; Li, Y.; Owen, T.B.; Wong, A.Y.; Yip, H.Y.; Cao, J. Horseshoe crab genomes reveal the evolutionary fates of genes and microRNAs after three rounds (3R) of whole genome duplication. bioRxiv 2020. [CrossRef]

57. Kaya, M.; Baran, T.; Asan-Ozusaglam, M.; Cakmak, Y.S.; Tozak, K.O.; Mol, A.; Sezen, G. Extraction and characterization of chitin and chitosan with antimicrobial and antioxidant activities from cosmopolitan Orthoptera species (Insecta). Biotechnol. Bioprocess. Eng. 2015, 20, 168-179. [CrossRef]

Publisher's Note: MDPI stays neutral with regard to jurisdictional claims in published maps and institutional affiliations.

(C) 2020 by the authors. Licensee MDPI, Basel, Switzerland. This article is an open access article distributed under the terms and conditions of the Creative Commons Attribution (CC BY) license (http://creativecommons.org/licenses/by/4.0/). 